\title{
THREE-PHASE PACKED BED REACTOR WITH AN EVAPORATING SOLVENT-I. EXPERIMENTAL: THE HYDROGENATION OF 2,4,6-TRINITROTOLUENE IN METHANOL
}

\author{
K. B. VAN GELDER, J. K. DAMHOF, P. J. KROIJENGA and K. R. WESTERTERP ${ }^{\dagger}$ \\ Department of Chemical Engineering, Twente University of Technology, PO Box 217, 7500 AE Enschede, \\ Netherlands
}

(Received 22 December 1988; accepted 26 October 1989)

\begin{abstract}
In this paper we present experimental data on the three-phase hydrogenation of 2,4,6trinitrotoluene (TNT) to triaminotoluene. The experiments are performed in a cocurrent upflow packed bed reactor. Methanol is used as an evaporating solvent. The influence of the main operating parameters, the reactor pressure, the feed temperature and the molar ratio of hydrogen to TNT in the feed, are investigated experimentally. A rapid deactivation of the catalyst was observed. The rate of deactivation was investigated by performing experiments at standardized conditions at regular time intervals and by continuous operation of the reactor. Several experiments were done to find out if the catalyst could be regenerated in situ. This regeneration proved successful: the catalyst activity was practically equal to the initial one.
\end{abstract}

\section{INTRODUCTION}

In our laboratory we are investigating catalytic hydrogenation reactions in three-phase systems. Our purpose is to develop a reactor that is suitable for use in the fine chemicals industry. The reactions we are interested in take place in the liquid phase at the catalyst surface and are highly exothermic and complex. We are aiming at high yields for intermediate products. This a.o. implies that we must have a good control over the temperature in the reactor. Therefore we have chosen to use an evaporating solvent to absorb and remove most of the reaction heat.

As a model reaction we have chosen the hydrogenation of 2,4,6-trinitrotoluene (TNT) to triaminotoluene (TAT). The kinetics of this reaction using a $\mathrm{Pd}$ on carbon catalyst in a slurry reactor have been studied extensively in our laboratory. The hydrogenation of TNT is a complex and highly exothermic reaction with a heat effect of $-1850 \mathrm{~kJ} / \mathrm{mol}$ of TNT for complete conversion to TAT.

The amount of heat absorbed by evaporation of the solvent will be a function of the solvent vapor pressure and the amount of inert gas present in the system. In Appendix I the influence of the pressure and the gas flow rate on the amount of solvent that evaporates is discussed using a simple model. The amount of heat absorbed by evaporation of the solvent will rise exponentially when the temperature is close to the boiling point of the solvent: the temperature can never exceed the boiling point of the solvent at the prevailing pressure [sec Westerterp and Crombeen (1983), and Appendix].

In this paper we present the results that were obtained in our miniplant on the hydrogenation of TNT using methanol as the evaporating solvent. In the accompanying paper (van Gelder et al., 1990) we

\footnotetext{
tAuthor to whom correspondence should be addressed.
}

will model our system and compare the model calculations to the experimental data. It was observed that the catalyst deactivates quickly. Therefore, regeneration experiments were done in order to find out if the catalyst can be regenerated in situ.

\section{MODEL REACTION}

The hydrogenation of 2,4,6-trinitrotoluene to triaminotoluene was chosen as a model reaction. The kinetics of this reaction with a $\mathrm{Pd}$ on carbon catalyst in a slurry reactor have been extensively studied in our laboratory [see Janssen et al. (1987)]. The reaction scheme was found to be a complex network of parallel and consecutive reactions. Not all possible reaction intermediates could be positively identified.

To describe the consumption of hydrogen in this reaction network a lumped system of three consecutive reactions was used:

$$
\begin{aligned}
& \text { TNT }+2 \mathrm{H}_{2} \stackrel{\mathrm{r}_{1}}{\longrightarrow} \text { DNHAT }+\mathrm{H}_{2} \mathrm{O} \\
& \text { DNHAT }+4 \mathrm{H}_{2} \stackrel{\mathrm{r}_{2}}{\longrightarrow} \text { DANT }+4 \mathrm{H}_{2} \mathrm{O} \\
& \text { DANT }+3 \mathrm{H}_{2} \stackrel{r_{3}}{\longrightarrow} \text { TAT }+2 \mathrm{H}_{2} \mathrm{O}
\end{aligned}
$$

in which:

DNHAT = dinitrohydroxylaminetoluene

DANT = diaminonitrotoluene.

The reactions were found to be of the LangmuirHinshelwood type with different active sites for the nitro compounds and the hydrogen. For the time being the reaction rates are formulated as:

$$
r_{i}=k_{i} \frac{K_{i} C_{i}}{\left(1+\sum_{j=1}^{3} K_{j} C_{j}\right)} \frac{K_{\mathbf{H}} \frac{P_{\mathbf{H}}}{R T}}{\left(1+K_{\mathbf{H}} \frac{P_{\mathbf{H}}}{R T}\right)} m_{\mathrm{cat}} \mathrm{kmol} / \mathrm{m}^{3} \mathrm{~s}
$$


in which:

$$
\begin{aligned}
C_{i}= & \text { concentration of component } i\left(\mathrm{kmol} / \mathrm{m}^{3}\right) \\
k_{i}= & \text { reaction velocity constant }=k_{i \infty} \exp \left(-E_{\alpha t} /\right. \\
& T)(\mathrm{kmol} / \mathrm{kg} \text { catalyst } \mathrm{s}) \\
K_{i}= & \text { adsorption constant }=K_{i \infty} \exp \left(H_{\alpha i} / T\right)\left(\mathrm{m}^{3} /\right. \\
& \text { kmol) } \\
P_{\mathrm{H}}= & \text { hydrogen partial pressure }\left(\mathrm{N} / \mathrm{m}^{2}\right) \\
R= & \text { gas constant }(\mathrm{J} / \mathrm{kmol} \mathrm{K}) \\
T= & \text { temperature }(\mathrm{K}) \\
m_{\mathrm{cat}}= & \text { mass of catalyst used }\left(\mathrm{kg} \text { catalyst } / \mathrm{m}^{3}\right) .
\end{aligned}
$$

It was assumed that TAT does not adsorb on the catalyst surface. Because the values for the parameters were obtained from a fit of the conversion profiles calculated to the measured hydrogen consumption, these rate equations can only be used to calculate the conversion profile and not to predict the product composition.

Investigations in our laboratory showed that the lumped reaction scheme presented above can be used to predict the stable operating points in a CSTR with a high order of accuracy over a wide range of operating conditions [see Janssen et al. (1987)].

\section{DESCRIPTION OF THE MINIPLANT}

A flow sheet of the miniplant is given in Fig. 1. The cocurrent upflow packed bed reactor consists of two concentric cylinders. The inner cylinder is used to hold the catalyst bed, the outer cylinder is designed for pressures up to $2.8 \mathrm{MPa}$ at $180^{\circ} \mathrm{C}$. By varying the length of the inner cylinder the length of the catalyst bed can be varied. Depending on the length of the inner cylinder liquid samples can be taken at 110,350 and $710 \mathrm{~mm}$ above the entrance to the bed. A detailed drawing of the reactor entrance section is given in Fig. 2. Thermocouples are placed at the same positions in the centre of the bed to measure the temperature profile over the bed. A heating jacket is installed around the reactor to preheat the reactor prior to each experiment, in this way shortening the time required to stabilize the reactor conditions.

The liquid is fed to the reactor from a supply vessel by means of a membrane pump. The liquid flows in an upward direction through the catalyst bed, over the top of the inner cylinder and downward in the annulus. It is collected in a buffer vessel. The gas leaves the reactor at the top and flows through a cooler where the evaporated solvent is condensed. The condensed solvent is collected in a second buffer vessel. The excess hydrogen leaves the system through a pressure control valve.

The miniplant is connected to a data acquisition system which constantly monitors the values of the key variables during the experiments. These values are saved at regular time intervals. The catalyst used is a shell catalyst of $0.08 \mathrm{wt} \%$ of Pd on $4.2 \times 4.2 \mathrm{~mm}$ porous cylindrical alumina pellets manufactured by Girdler-Süd Chemie A. G.. The apparent packing density of the catalyst is $780 \mathrm{~kg} / \mathrm{m}^{3}$ and the bed porosity is 0.37 . The reaction mixture was analysed on a Varian 3400 Gas Chromatograph using a $5 \mathrm{ft}$ $\times 1 / 8^{\prime \prime}$ Tenax $60 / 80$ mesh column. For a more detailed description of the miniplant we refer the reader to van Gelder (1988).

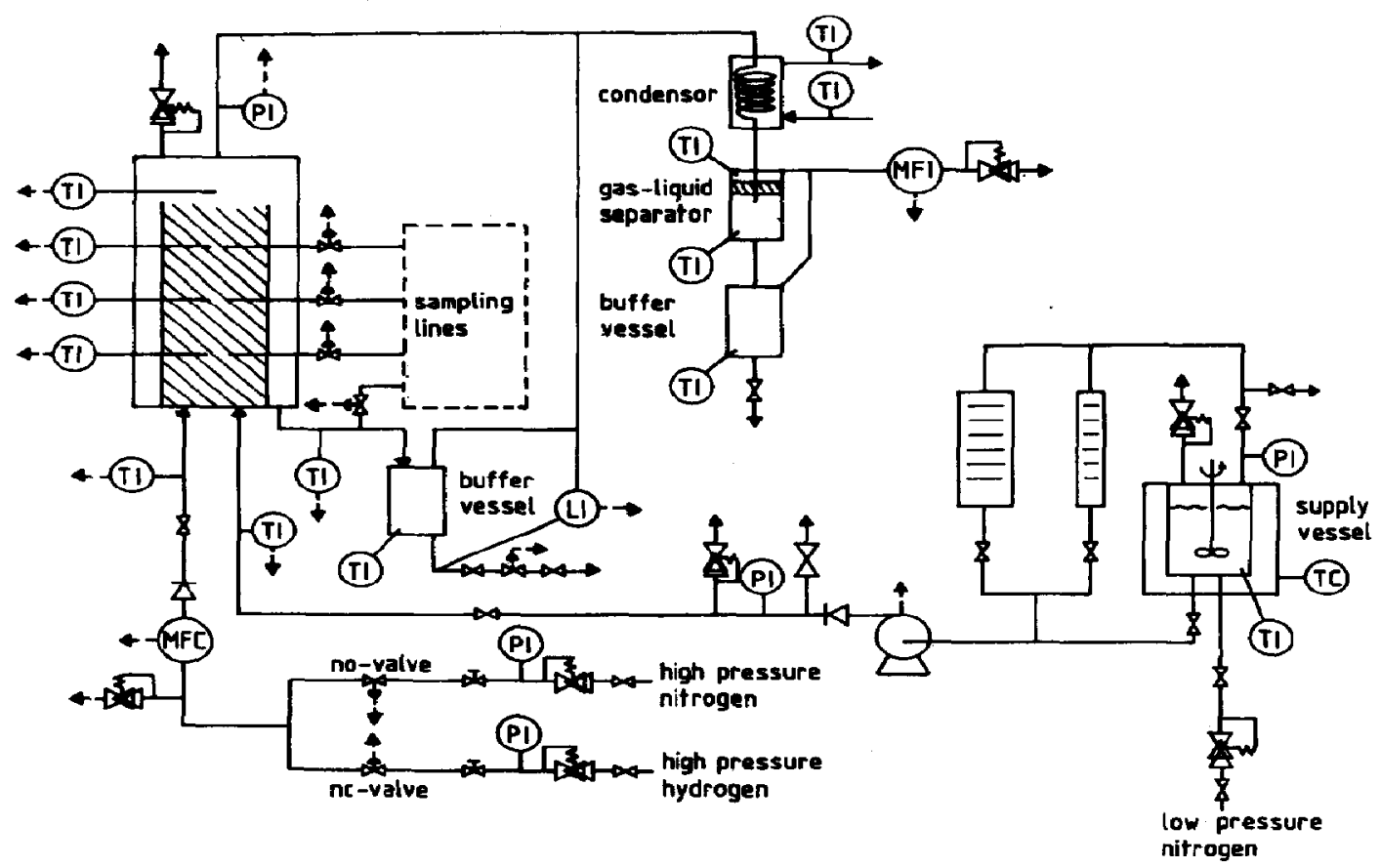

Fig. 1. Flow sheet of the miniplant. Instruments labelled with an arrow are connected to or controlled by the micro-computer. 


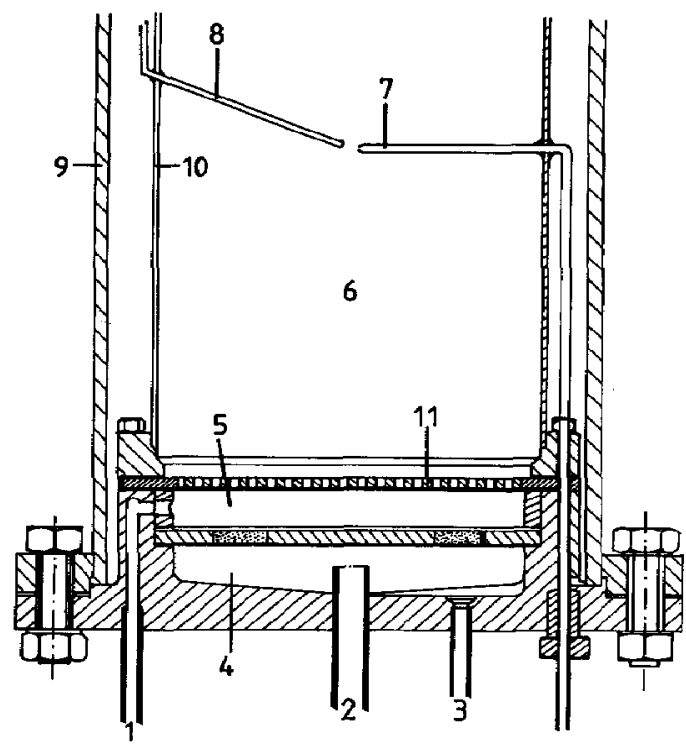

Fig. 2. Detailed drawing of the reactor entrance section and the sumpling and thermocouple locations: $1=$ liquid feed pipe, 2 = gas feed pipe, $3=$ drain, $4=$ gas entrance chamber, $5=$ gas-liquid mixing chamber, $6=$ catalyst bed, 7 $=$ sampling tubc, $8=$ thermocouple tube, $9=$ outer shell, $10=$ inner tube, $11=$ distributor.

\section{EXPERIMENTAL PROCEDURES}

Prior to each experiment the reactor was preheated in order to shorten the time it takes the system to stabilize. Stable operation was generally reached approximately $1 \mathrm{~h}$ after the introduction of the gas and the liquid to the reactor. A typical example of the temperatures measured as a function of the time expired after the introduction of gas and liquid in the reactor is given in Fig. 3.

Approximately $1 \mathrm{~h}$ after stable operation was reached the first sample of the liquid phase was taken. Each sample was analysed in duplicate on the gas chromatograph which took approximately $30 \mathrm{~min}$. Because the samples could only be kept for a short period the whole process of sampling and analysing at all the detection points was executed rapidly in a period between 1.5 and $2 \mathrm{~h}$.

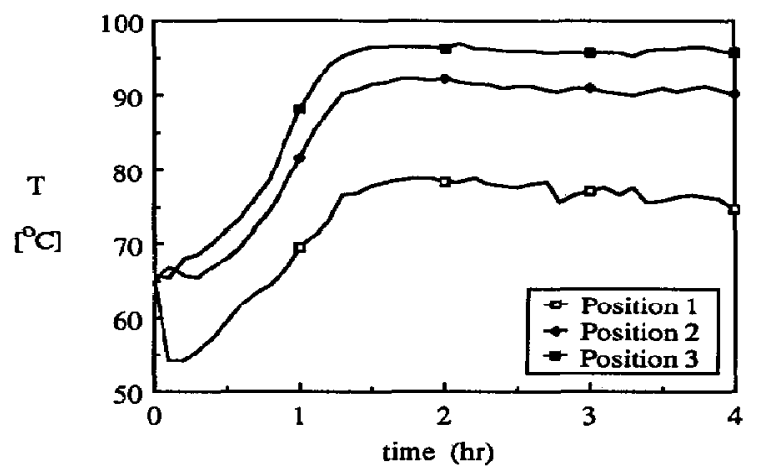

Fig. 3. Typical temperature profiles measured after the start of an experiment.
Two types of experiments were done: short steady state and long duration experiments. The short steady state experiment took $3-5 \mathrm{~h}$. The operating parameters were set at the start of the experiment and were held constant during the course of the experiment. Experiments under standard conditions were done at regular intervals in order to monitor the catalyst activity.

The catalyst deactivates relatively quickly. We suspect that this is caused by an irreversible adsorption of reaction intermediates on the active catalyst surface area. Because not all reaction intermediates can be rinsed out of the highly porous catalyst carrier after an experiment, the deactivation may continue during the time the reactor stands idle between two experiments. Therefore long duration experiments were done over a period of $2 \frac{1}{2}-3$ days continuously. During the first of these long duration experiments the operating parameters were held constant in order to evaluate the rate of deactivation under constant operating conditions. The second long duration experiment consisted of a series of short experiments, each lasting approximately $3 \mathbf{h}$, after which the operating conditions were changed.

\section{EXPERIMENTAL RESULTS AND DISCUSSION}

In the Appendix it is shown, using a simple model, that the amount of solvent that evaporates at a certain temperature and pressure is dependent on the amount of inert gas that is present. In our system the situation is more complicated because the system is not operated isothermally and also the amount of inert gas varies over the length of the reactor. The amount of inert gas present is equal to the amount of hydrogen that is fed to the reactor and not yet consumed by the reaction. As a measure for the amount of inert gas we have defined the hydrogen supply ratio $\alpha_{\mathrm{TAT}}$ as the quotient of the number of moles of hydrogen fed to the reactor per unit of time over the number of moles of hydrogen necessary for complete conversion of all TNT into TAT per unit of time. This means that if $\alpha_{\text {TAT }}=1$ exactly enough hydrogen is fed to the reactor to convert all TNT into TAT. If $\alpha_{\text {TAT }}>1$ then an excess of hydrogen is fed to the reactor.

\subsection{Influence of the operating variables}

The main operating variables that were studied experimentally are the reactor pressure, which determines the boiling point of the solvent; the feed temperature, which determines the initial reaction rate; and the hydrogen supply rate $\alpha_{\text {TAT }}$, which is a measure for the amount of inert gas present in the reactor.

$A$ list of all experiments and the measured temperature and conversion data is given in Table 1. The experiments are listed in order of sequence in time. The table indicates when the catalyst bed has been changed. Experiments with an $S$ after the number are standard experiments done under standard conditions to monitor the activity of the catalyst. It should be noted that the standard conditions were changed after experiment $10 \mathrm{~S}$. 
Table 1. Experimental conditions and results

\begin{tabular}{|c|c|c|c|c|c|c|c|c|c|c|c|c|c|c|}
\hline \multirow[b]{2}{*}{ Code $^{\dagger}$} & \multicolumn{7}{|c|}{ Operating conditions } & \multicolumn{7}{|c|}{ Experimental data } \\
\hline & $\begin{array}{c}P \\
(\mathrm{MPa})\end{array}$ & $\begin{array}{c}\Phi_{\mathbf{L}} \\
(\mathbf{l} / \mathbf{h})\end{array}$ & $\begin{array}{c}\Phi_{\mathrm{G}} \\
(\mathrm{Nl} / \mathrm{min})\end{array}$ & 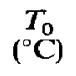 & $\underset{(\mathbf{m})}{L}$ & $\alpha_{\text {TAT }}$ & $\gamma$ & $\begin{array}{c}T_{1} \\
\left({ }^{\circ} \mathrm{C}\right]\end{array}$ & $\begin{array}{c}T_{2} \\
\left({ }^{\circ} \mathrm{C}\right)\end{array}$ & $\begin{array}{c}T_{\mathbf{3}} \\
\left({ }^{\circ} \mathbf{C}\right)\end{array}$ & $\zeta_{1}$ & $\zeta_{2}$ & $\zeta_{\mathbf{3}}$ & $\zeta_{\mathbf{L}}$ \\
\hline $1 \mathrm{~S}$ & 0.8 & 9.0 & 17.5 & 55.5 & 0.97 & 4.73 & 4.46 & 93 & 97 & 94 & 0.84 & 0.98 & 1.00 & 1.00 \\
\hline 2 & 0.8 & 9 & 22.0 & 56.5 & 0.97 & 2.89 & 3.68 & 94 & 111 & 111 & 0.22 & 0.87 & 0.98 & 0.99 \\
\hline 3 & 0.8 & 9 & 35.5 & 56 & 0.97 & 5.65 & 2.25 & 80 & 96 & 100 & 0.43 & 0.93 & 0.99 & 1.00 \\
\hline 4 & 0.8 & 9 & 9.5 & 54 & 0.97 & 1.51 & 8.40 & 90 & 97 & 101 & 0.10 & 0.20 & 0.20 & 0.22 \\
\hline $5 \mathrm{~S}$ & 0.8 & 9.0 & 17.5 & 56.5 & 0.97 & 4.73 & 4.46 & 71 & 81 & 81 & 0.06 & 0.06 & 0.08 & 0.08 \\
\hline $6 S$ & 0.8 & 9 & 17.8 & 55 & 0.97 & 4.81 & 4.39 & 85 & 92 & 93 & 0.94 & 0.99 & 0.99 & 1.00 \\
\hline 7 & 0.4 & 9.7 & 9.7 & 56 & 0.97 & 1.43 & 8.93 & 78 & 91 & 96 & 0.24 & 0.66 & 0.85 & 0.87 \\
\hline 8 & 1.2 & 9 & 9.5 & 55.5 & 0.97 & 1.51 & 8.40 & 105 & 121 & 125 & 0.33 & 0.93 & 0.97 & 0.99 \\
\hline 9 & 1.2 & 8.1 & 21.2 & 54.5 & 0.97 & 3.75 & 3.40 & 86 & 102 & 110 & 0.05 & 0.30 & 0.60 & 0.62 \\
\hline 10 & 0.8 & 9.0 & 15 & 65 & 0.97 & 2.39 & 5.35 & \multicolumn{7}{|c|}{ Experiment to measure deactivation } \\
\hline $11 \mathrm{~S}$ & 0.5 & 10.6 & 17.8 & 50 & 0.71 & 2.40 & 5.29 & 79 & 96 & 99 & 0.43 & 0.64 & 0.80 & 0.80 \\
\hline 12 & 0.4 & 7.8 & 18.0 & 51 & 0.71 & 3.30 & 3.85 & 70 & 83 & 87 & 0.34 & 0.60 & 0.68 & 0.68 \\
\hline 13 & 0.4 & 7.7 & 12.0 & so & 0.71 & 2.23 & 5.71 & 69 & 87 & 90 & 0.40 & 0.60 & 0.67 & 0.67 \\
\hline 14 & 0.6 & 6.8 & 12.0 & 49.5 & 0.71 & 2.53 & 5.03 & 86 & 103 & 106 & 0.31 & 0.68 & 0.77 & 0.77 \\
\hline $15 \mathrm{~S}$ & 0.5 & 10.6 & 17.8 & 52 & 0.71 & 2.40 & 5.30 & 64 & 82 & 88 & 0.13 & 0.23 & 0.39 & 0.39 \\
\hline $16 \mathrm{~S}$ & 0.5 & 11.1 & 17.8 & 52.5 & 0.71 & 2.30 & 5.55 & 60 & 62 & 66 & 0.07 & 0.09 & 0.11 & 0.11 \\
\hline 17 & 0.8 & 6.3 & 18.0 & 50 & 0.71 & 4.09 & 3.10 & 68 & 84 & 90 & 0.17 & 0.34 & 0.52 & 0.52 \\
\hline \multicolumn{15}{|c|}{ Catalyst regenerated: next experiment with regenerated catalyst } \\
\hline $18 \mathrm{~S}$ & 0.5 & 10.9 & 17.8 & 52 & 0.71 & 2.34 & 5.45 & 77 & 95 & 94 & 0.47 & 0.63 & 0.65 & 0.65 \\
\hline $19 \mathrm{~S}$ & 0.5 & 11.0 & 17.8 & 50 & 0.97 & 2.32 & 5.50 & 89 & 98 & 102 & 0.58 & 0.84 & 0.96 & 0.95 \\
\hline 20 & 0.4 & 7.7 & 2.6 & 50 & 0.97 & 0.48 & 26.3 & 92 & 95 & 100 & 0.25 & 0.36 & 0.36 & 0.38 \\
\hline $21 \mathrm{~S}$ & 0.5 & 10.8 & 17.8 & 50 & 0.97 & 2.36 & 5.40 & 90 & 99 & 104 & 0.53 & 0.70 & 0.78 & 0.78 \\
\hline 22 & 0.4 & 7.6 & 7.9 & 50 & 0.97 & 1.49 & 8.55 & 91 & 96 & 101 & 0.52 & 0.64 & 0.68 & 0.69 \\
\hline $23 \mathrm{~S}$ & 0.5 & 11.2 & 17.8 & 50 & 0.97 & 2.27 & 5.60 & 86 & 97 & 102 & 0.39 & 0.61 & 0.72 & 0.72 \\
\hline 24 & 0.4 & 7.7 & 7.9 & 55 & 0.97 & 1.47 & 8.70 & 89 & 96 & 100 & 0.53 & 0.62 & 0.67 & 0.67 \\
\hline $25 \mathrm{~S}$ & 0.5 & 11.1 & 17.8 & 50 & 0.97 & 2.30 & 5.55 & 78 & 92 & 100 & 0.33 & 0.56 & 0.64 & 0.65 \\
\hline 26 & 0.4 & 7.6 & 2.6 & 55 & 0.97 & 0.49 & 26.3 & 80 & 96 & 100 & 0.18 & 0.33 & 0.40 & 0.43 \\
\hline $27 \mathrm{~S}$ & 0.5 & 10.6 & 17.8 & 50 & 0.97 & 2.40 & 5.30 & 88 & 99 & 103 & 0.42 & 0.79 & 0.99 & 1.00 \\
\hline 28 & 0.4 & 7.5 & 18.5 & 55 & 0.97 & 3.53 & 3.60 & 67 & 85 & 89 & 0.20 & 0.58 & 0.75 & 0.75 \\
\hline 29 & 0.4 & 7.3 & 18.5 & 65 & 0.97 & 3.63 & 3.50 & 71 & 87 & 91 & 0.21 & 0.58 & 0.78 & 0.79 \\
\hline 30 & 0.4 & 7.7 & 12.3 & 50 & 0.97 & 2.29 & 5.55 & 70 & 90 & 94 & 0.25 & 0.55 & 0.72 & 0.73 \\
\hline 31 & 0.5 & 7.2 & 12.3 & 50 & 0.97 & 2.44 & 5.20 & 86 & 100 & 104 & 0.35 & 0.67 & 0.80 & 0.80 \\
\hline 32 & 0.3 & 7.7 & 12.3 & 50 & 0.97 & 2.29 & 5.55 & 65 & 75 & 80 & 0.10 & 0.35 & 0.53 & 0.56 \\
\hline $33 \mathrm{~S}$ & 0.5 & 11.0 & 17.8 & 50 & 0.97 & 2.32 & 5.50 & 80 & 94 & 100 & 0.18 & 0.47 & 0.68 & 0.68 \\
\hline 34 & 0.4 & 7.4 & 11.8 & 60 & 0.97 & 2.28 & 5.60 & 78 & 89 & 95 & 0.24 & 0.52 & 0.66 & 0.66 \\
\hline 35 & 0.4 & 7.4 & 17.8 & 60 & 0.97 & 3.44 & 3.70 & 72 & 84 & 89 & & 0.47 & 0.68 & 0.68 \\
\hline 36 & 0.4 & 7.5 & 23.7 & 60 & 0.97 & 4.52 & 2.80 & 66 & 78 & 84 & 0.16 & 0.42 & 0.66 & 0.68 \\
\hline $37 \mathrm{~S}$ & 0.5 & 10.3 & 17.8 & 50 & 0.97 & 2.47 & 5.15 & 79 & 93 & 99 & 0.19 & 0.46 & 0.65 & 0.67 \\
\hline 38 & 0.4 & 7.4 & 9.2 & 60 & 0.97 & 1.78 & 7.15 & 82 & 92 & 96 & 0.36 & 0.54 & 0.63 & 0.63 \\
\hline 39 & 0.4 & 14.1 & 13.9 & 60 & 0.97 & 1.41 & 9.00 & 77 & 88 & 93 & 0.08 & 0.22 & 0.41 & 0.48 \\
\hline 40 & 0.4 & 7.5 & 5.9 & 60 & 0.97 & 1.13 & 11.4 & 84 & 93 & 97 & 0.42 & 0.49 & 0.56 & 0.54 \\
\hline 41 & 0.4 & 7.5 & 3.0 & 60 & 0.97 & 0.57 & 22.2 & 89 & 96 & 100 & 0.27 & 0.42 & 0.49 & 0.51 \\
\hline 42 & 0.5 & 10.5 & 14.2 & 50 & 0.97 & 1.94 & 6.58 & 80 & 90 & 97 & 0.18 & 0.40 & 0.59 & 0.60 \\
\hline 43 & 0.25 & 7.7 & 7.1 & 60 & 0.97 & 1.32 & 9.60 & 63 & 69 & 73 & 0.08 & 0.17 & 0.26 & 0.27 \\
\hline 44 & 0.25 & 7.6 & 14.2 & 60 & 0.97 & 2.67 & 4.75 & 52 & 57 & 61 & 0.06 & 0.10 & 0.19 & 0.21 \\
\hline $45 \mathrm{~S}$ & 0.5 & 10.6 & 17.8 & 50 & 0.97 & 2.40 & 5.30 & 77 & 85 & 92 & 0.11 & 0.32 & 0.47 & 0.47 \\
\hline
\end{tabular}

A space between rows indicates that the reactor is filled with fresh catalyst.

tExperiments coded with an " $\mathrm{S}$ " are experiments done under standard conditions in order to monitor catalyst activity.

5.1.1. Influence of the reactor pressure. The influence of pressure can best be illustrated by comparing experiments 30, 31 and 32, listed in Table 2. The temperature and conversion data measured are given in Fig. 4 as a function of the reactor pressure. The temperature rises with increasing pressure, as does the conversion. The pressure increase from 0.3 to $0.5 \mathrm{MPa}$ results in an increase of the boiling point of pure methanol from 96 to $113^{\circ} \mathrm{C}$ but the temperature rise in the reactor is slightly greater than the increase in the boiling point of the solvent. This is caused by the increase in conversion and consequently by the higher reaction heat production.

5.1.2. Infiuence of the hydrogen supply ratio $\alpha_{T A T}$. The influence of the hydrogen supply ratio $\alpha_{\text {TAT }}$ can best be illustrated on the basis of experiments 34,35 , $36,38,40$ and 41 . The temperature and conversion data measured are listed in Table 3 and are plotted in Fig. 5. If $\alpha_{\mathrm{TAT}}$ is smaller than 1 the conversion is 
Three-phase packed bed reactor with an evaporating solvent--I

Table 2. Influence of the pressure on the measured temperature and conversion profiles

\begin{tabular}{ccccccccc}
\hline Code & $\begin{array}{c}P \\
(\mathrm{MPa})\end{array}$ & $\begin{array}{c}T_{1} \\
\left({ }^{\circ} \mathrm{C}\right)\end{array}$ & $\begin{array}{c}T_{2} \\
\left({ }^{\circ} \mathrm{C}\right)\end{array}$ & $\begin{array}{c}T_{3} \\
\left({ }^{\circ} \mathrm{C}\right)\end{array}$ & $\zeta_{1}$ & $\zeta_{2}$ & $\zeta_{3}$ & $\zeta_{2}$ \\
\hline 32 & 0.3 & 65 & 75 & 80 & 0.10 & 0.35 & 0.53 & 0.56 \\
30 & 0.4 & 70 & 90 & 94 & 0.25 & 0.55 & 0.72 & 0.73 \\
31 & 0.5 & 86 & 100 & 104 & 0.35 & 0.67 & 0.80 & 0.80 \\
\hline
\end{tabular}

Note: experimental data as in Table 1.
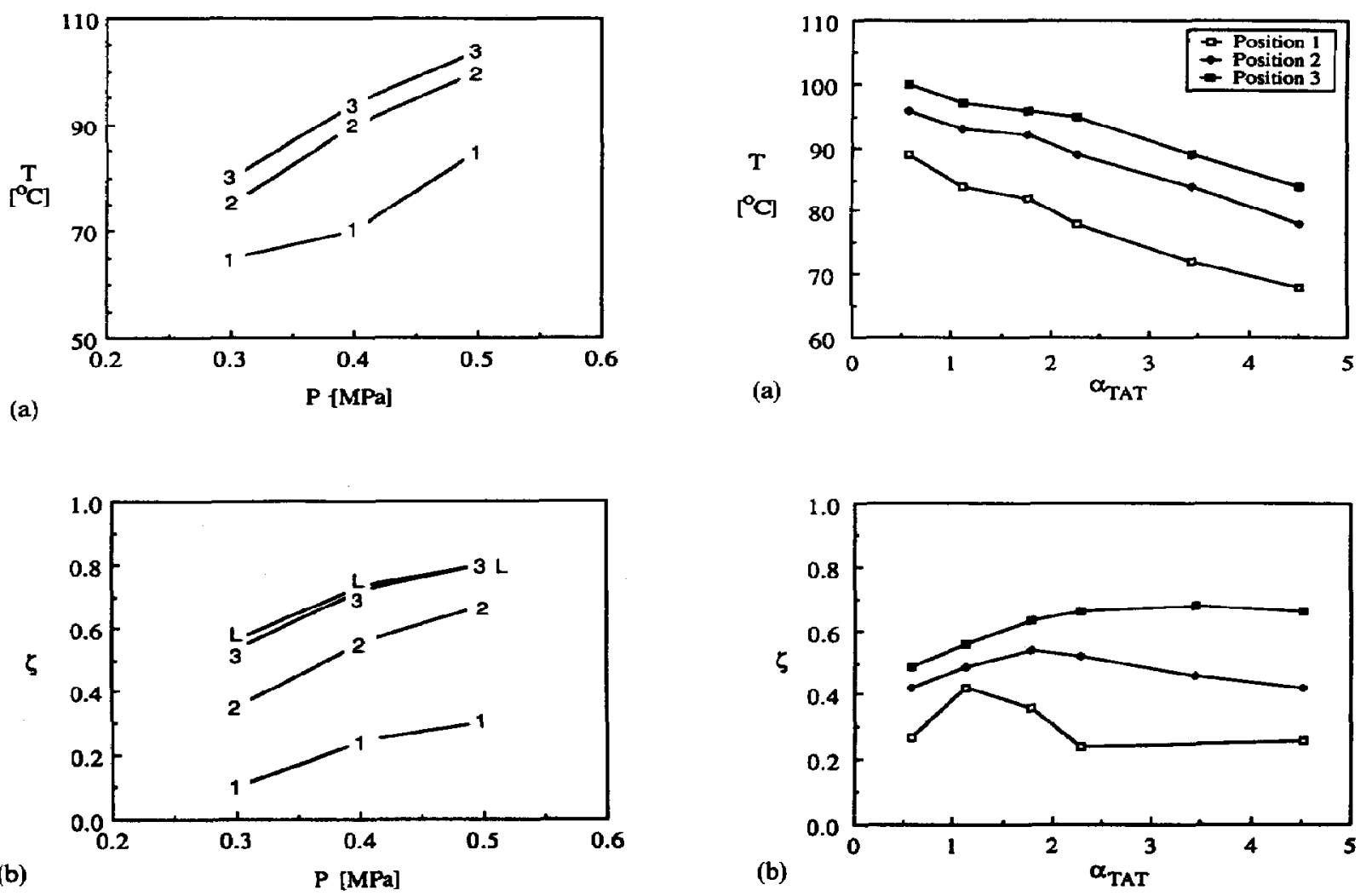

Fig. 4. Influence of the reactor pressure on the measured temperatures (a) and on the measured conversion (b): 1 $=$ first detection point, 2 = second detection point, 3 $=$ third detection point. $L$ denotes quantity at reactor exit.

Fig. 5. Influence of the hydrogen supply ratio $\alpha_{T A T}$ on the experimental temperatures (a) and on the conversion (b) as measured at the detection points. Experimental conditions and data are given in Tables 1 and 3.

Table 3. Influence of the hydrogen supply ratio $\alpha_{\text {TAT }}$ on the measured temperature and conversion profiles

\begin{tabular}{lcrrrrrrrr}
\hline Code & $\alpha_{\text {TAT }}$ & $\begin{array}{c}\left.T_{1}{ }^{\circ}\right) \\
\left({ }^{\circ} \mathbf{C}\right)\end{array}$ & $\begin{array}{c}\left.T_{2}{ }^{\circ} \mathbf{C}\right) \\
T_{3}\end{array}$ & $\zeta_{1}$ & $\zeta_{2}$ & $\zeta_{3}$ & $\zeta_{L}$ \\
\hline 40 & 0.57 & 89 & 96 & 100 & 0.27 & 0.42 & 0.49 & 0.51 \\
38 & 1.13 & 84 & 93 & 97 & 0.42 & 0.49 & 0.56 & 0.54 \\
34 & 1.78 & 82 & 92 & 96 & 0.36 & 0.54 & 0.63 & 0.63 \\
35 & 3.44 & 78 & 89 & 95 & 0.24 & 0.52 & 0.66 & 0.66 \\
36 & 4.52 & 68 & 78 & 84 & 0.26 & 0.42 & 0.66 & 0.68 \\
\hline
\end{tabular}

Note: experimental conditions as in Table 1. 
limited by the amount of hydrogen that is available. For $\alpha_{\text {TAT }}<1$ the maximum conversion is equal to $x_{\text {TAT }}$. The maximum conversion cannot be reached completely because then the hydrogen partial pressure would drop to zero, stopping the reaction. We expect the temperature level in the reactor to rise with increasing $\alpha_{\mathrm{TAT}}$ until it is close to the boiling point, which for the experiments in Table 3 equals $105^{\circ} \mathrm{C}$. The final temperature for experiment 41 with a hydrogen supply ratio of 0.57 is $100^{\circ} \mathrm{C}$, which is indeed close to the boiling point of methanol.

Increasing $\alpha_{\text {TAT }}$ above 1 has two counteractive effects. First, more solvent will evaporate due to the presence of more hydrogen, resulting in lower temperatures and consequently lower reaction rates. Second, due to the lower temperature the hydrogen partial pressure will be higher and also the adsorption constant for hydrogen increases with decreasing temperature, both resulting in an increasing reaction rate.

In the first part of the reactor the first effect dominates, resulting in a decrease of the conversion. In the second part of the reactor the second effects dominate and the loss of conversion in the first part of the reactor is completely made up for: the conversion at the exit of the reactor rises. Only at high values of $\alpha_{\text {TAT }}$ does the influence of the decreasing temperature dominate.

5.1.3. Influence of the feed temperature. The influence of the feed temperature can be illustrated on the basis of experiments 28 and 29 given in Table 4 . It is clear that the influence of the feed temperature is relatively small. An increase of $10^{\circ} \mathrm{C}$ in the feed temperature is quite large, yet the temperature and conversion are hardly affected. This is caused by the inherent moderation in using an evaporating system. A higher feed temperature will result in a larger evaporation rate and consequently a lower partial pressure of hydrogen. This will partly compensate for the influence of the higher temperatures on the reaction rate.

\subsection{Disturbances in the operating parameters}

An important aspect of reactor operation is the handling of sudden disturbances in the operating parameters. During the experiments several unintentional changes in the operating parameters occurred. After such a change the values for the operating variables were adjusted as soon as possible. The conditions in the reactor generally returned back to normal in 15-20 min, which is in the order of magnitude of the residence time of the liquid phase. Therefore no information on the transient conversion profiles could be obtained and only the transient temperature profiles at the detection points were measured. We will now discuss some of the disturbances and the resulting transient temperature profiles as measured.

5.2.1. Changes in the feed gas flow rate. During experiment 34 the feed gas flow rate suddenly dropped from 12 to around $6 \mathrm{Nl} / \mathrm{min}$. Consequently the hydrogen supply ratio $\alpha_{\text {TAT }}$ was lowered and the temperature in the reactor started to rise. The response was practically immediate as can be seen in Fig. 6. After restoration of the feed gas flow rate the temperature level returned to the old value in approximately 20

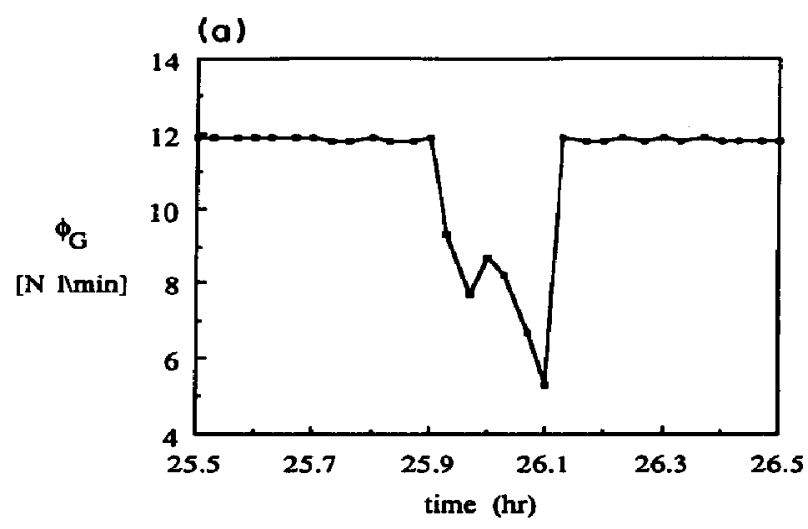

(b)

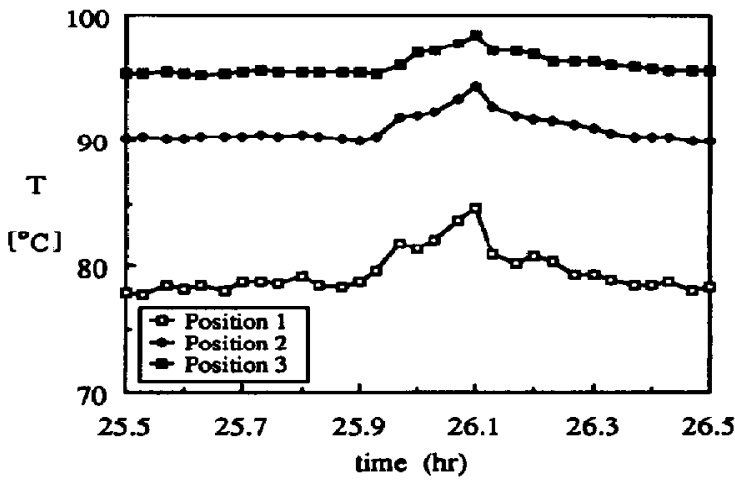

Fig: 6. A short variation in the feed gas flow rate as measured during experiment 34 (a) and the transient temperature response (b).

Table 4. Influence of the feed temperature on the measured conversion and temperature profiles

\begin{tabular}{cccccccccc}
\hline Code & $\begin{array}{c}T_{0} \\
\left({ }^{\circ} \mathrm{C}\right)\end{array}$ & $\begin{array}{c}T_{1} \\
\left({ }^{\circ} \mathrm{C}\right)\end{array}$ & $\begin{array}{c}T_{2} \\
\left.{ }^{\circ} \mathrm{C}\right)\end{array}$ & $\begin{array}{c}T_{3} \\
\left({ }^{\circ} \mathrm{C}\right)\end{array}$ & $\zeta_{1}$ & $\zeta_{2}$ & $\zeta_{3}$ & $\zeta_{L}$ \\
\hline 28 & 55 & 67 & 85 & 89 & 0.20 & 0.58 & 0.75 & 0.75 \\
29 & 65 & 71 & 87 & 91 & 0.21 & 0.58 & 0.78 & 0.79
\end{tabular}

Note: experimental conditions as in Table 1. 
min, which is in the order of magnitude of the residence time of the liquid phase.

5.2.2. Changes in the reactor pressure. During experiment 44 a short-circuit in a thermostat blew a fuse and disabled the pressure controller which was connected to the same power supply line. The pressure controller was put back in operation within $15 \mathrm{~min}$. The pressure increase in the reactor could be limited to $0.1 \mathrm{MPa}$. The temperature level in the reactor started to rise. When the pressure was restored to the old value the temperatures returned to their former level in approximately $25 \mathrm{~min}$, which again is in the order of magnitude of the residence time of the liquid phase. The pressure and temperature response curves measured are given in Fig. 7.

The disturbances in the operating parameters are smoothed in approximately $20 \mathrm{~min}$ while stable operation after start-up needs about $80 \mathrm{~min}$. This is caused by the fact that the deviations from the stationary conditions are relatively small in the first case, whereas in the second case stationary operation has not yet been reached. After start-up it takes once the residence time to fill the reactor and, depending on the deviation from final stable conditions, another one to three residence times for the concentration and temperature profiles to fully develop and stabilize.

Very interesting transient temperature profiles resulting from an instable reactor pressure were observed during experiment 20 . During this experiment

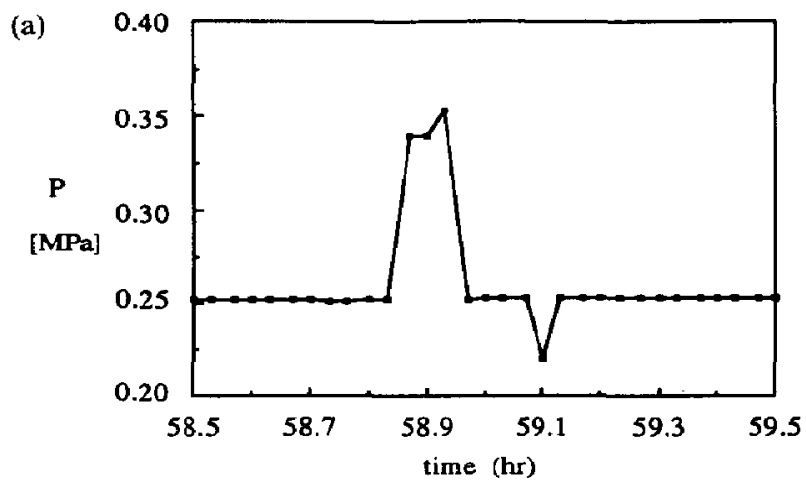

(b)

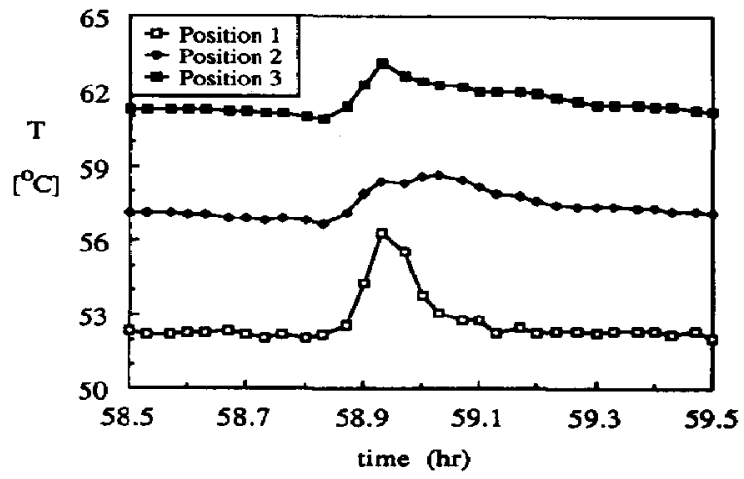

Fig. 7. Pressure variation during experiment 44 (a) and the transient temperature response (b). the hydrogen supply ratio was 0.48 . Because practically all the hydrogen was consumed it was hard to control the reactor pressure, especially when emptying the product buffer vessel. The pressure and temperature profiles measured during this experiment are given in Fig. 8. The temperature response is practically parallel to the slowly varying pressure. The temperature in the top of the reactor constantly remains around $5^{\circ} \mathrm{C}$ below the boiling point of the solvent which is $104^{\circ} \mathrm{C}$ at $0.39 \mathrm{MPa}$ and $99^{\circ} \mathrm{C}$ at $0.33 \mathrm{MPa}$. For a pressure decrease we expect the temperatures in the reactor to respond almost immediately as all excess heat can be purged very quickly by evaporation of the solvent. For a pressure increase we expect the responsc to be slower because the catalyst bed and the gas and liquid phases still have to be heated up. The reason why the transient temperature profile in Fig. 8 is practically parallel to the pressure profile is that the pressure variation is slow, giving the reaction plenty of time to produce the heat needed to increase the temperatures.

5.2.3. Overflowing buffer vessel. During some experiments the differential pressure indicator of the product buffer vessel was out of use. This vessel then had to be emptied manually by the operator at regular intervals. When this is not done on time the vessel is

(a)

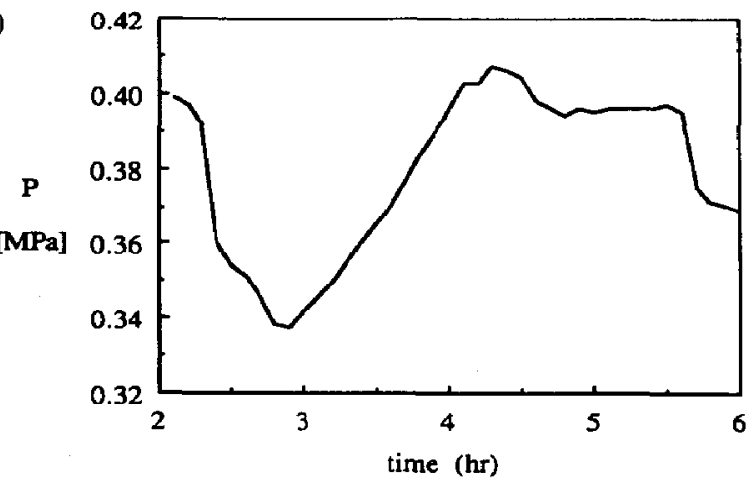

(b)

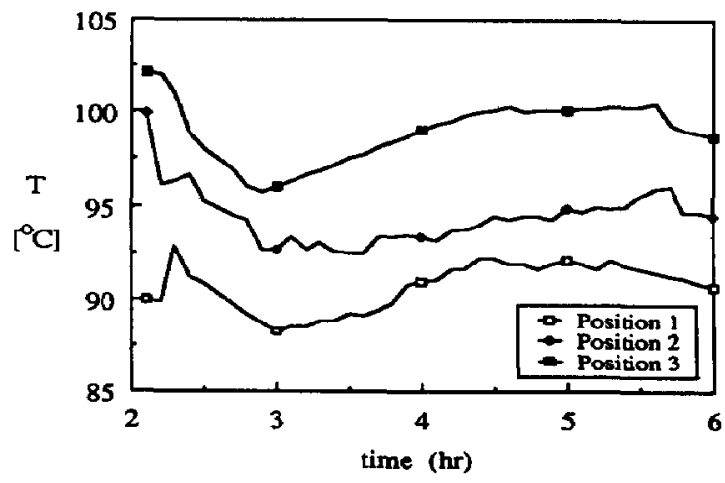

Fig. 8. Slowly varying pressure during experiment 20 (a) and the transient temperature response (b). The reactor is operating at $\alpha_{\text {TAT }}=0.48$ with practically complete conversion of all hydrogen. 


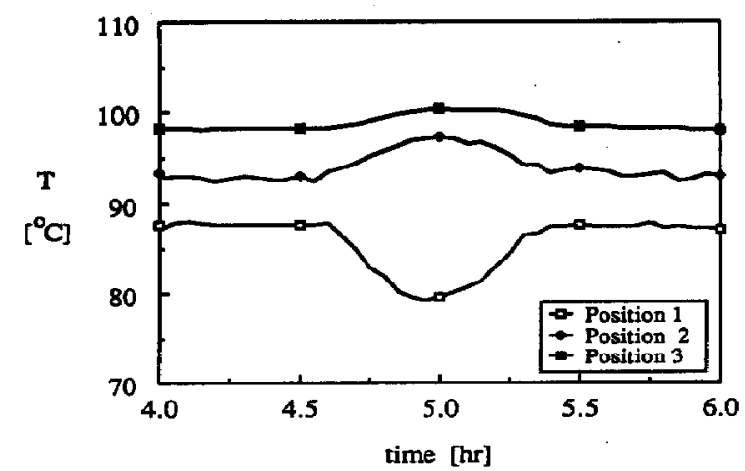

Fig. 9. Temperature response to overflowing of the product buffer vessel during experiment 26.

filled completely and a liquid level starts to build up in the annulus between the catalyst bed and the outer cylinder of the reactor. As soon as the buffer vessel is full the measured temperature at the liquid exit of the reactor starts to decrease because no more hot liquid flows out of the reactor. When the annulus is filled the backmixing of heat caused by the liquid flowing downward in the annulus is suppressed in the corresponding part of the reactor. This causes the temperature to decrease in the part of the catalyst bed that is surrounded by the stagnant liquid. In the part of the reactor above the level of the stagnant liquid in the annulus the backmixing of heat still takes place and there the reaction rate will increase strongly because of higher partial pressure of hydrogen and the higher reactant concentrations in the liquid phase, causing a temperature rise in the upper section of the catalyst bed. The response curves as measured during experiment 26 are given in Fig. 9.

\section{CATALYST DEACTIVATION AND REGENERATION}

\subsection{Deactivation}

During our experiments we observed that the activity of the catalyst decreased rapidly. Therefore experiments were executed under standardized conditions at regular intervals in order to monitor the catalyst activity. The rapid deactivation can be observed by comparing for instance experiments $1 S$ and $5 S$ and the experiments 19S, 21S, 23S and $25 \mathrm{~S}$ in Table 1. Generally the catalyst activity had decreased so much after 5-6 experiments that the catalyst had to be changed. The most likely cause for this rapid deactivation is an irreversible adsorption of reaction intermediates on the catalyst surface. Because the reaction mixture contains nitro-groups, partially hydrogenated nitro-groups and amino-groups it is also possible that polymers are formed and deposited on the catalyst surface.

After each experiment the catalyst bed is rinsed with methanol and kept under nitrogen during the time the reactor is not in operation. Because of the porosity of the catalyst carrier it is not possible to completely rinse all intermediates from the reactor and therefore we strongly suspect that the deactiva- tion continues during the time the reactor stands idle between experiments. The results from the experiments $15 \mathrm{~S}$ and 16S, which were done 3 days apart, seem to confirm this. In order to know the catalyst activity for each single experiment we therefore decided from experiment 19 onwards to execute a short standard experiment before bringing the reactor to the desired operating conditions.

To eliminate the possible deactivation in the idle time two long duration experiments were done during

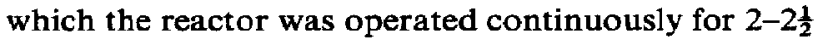
days. The first of these long duration experiments is experiment 10 , during which the operating conditions were held constant and the decrease in temperature and conversion were measured over a period of 2 days. The second long duration experiment consisted of a series of short experiments: the experiments $27 \mathrm{~S}-45 \mathrm{~S}$.

The temperature and conversion profiles measured as a function of time for experiment 10 are given in Fig. 10(a) and (b), where we see that the temperature decreases rapidly during the first few hours of operation but then the decrease slows down and becomes practically constant. This initial temperature decrease must also he partly attributed to malfunctioning of the mass flow controller which slowly increased the feed gas flow rate until the desired value was reached after approximately $3 \mathrm{~h}$. The measured temperatures
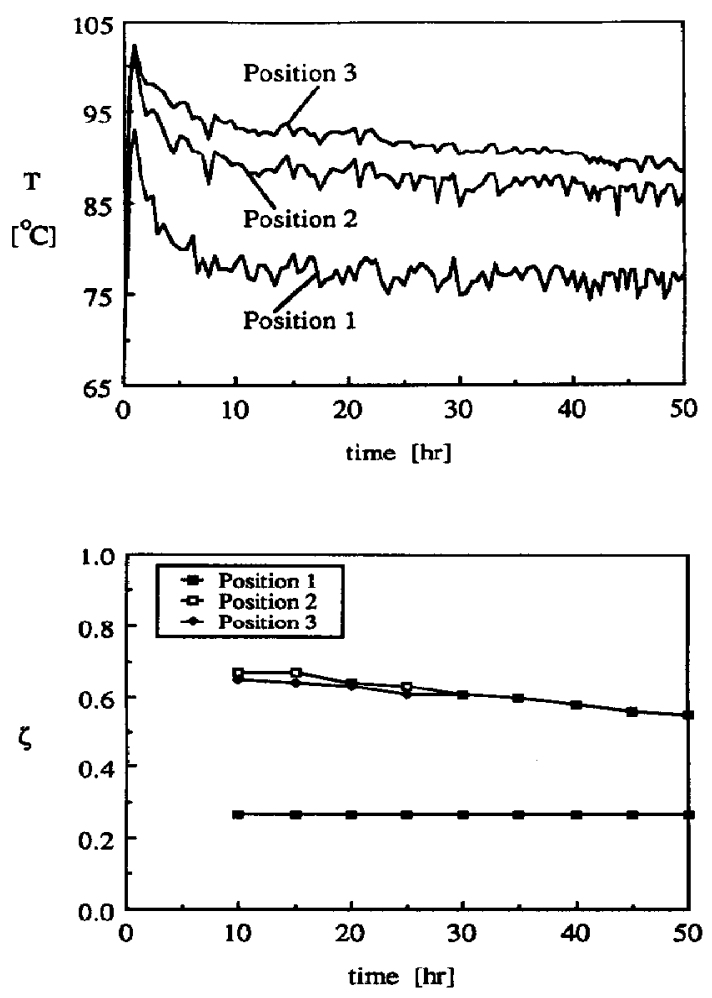

Fig. 10. Temperatures (a) and conversion (b) as measured during continuous operation of the reactor. Experimental conditions are given in Table 1 , experiment 10 . 
and conversions after $10,20,30,40$ and $50 \mathrm{~h}$ of operation are given in Table 5 .

During the second long duration experiment standard experiments were executed after $0,22,35$ and $60 \mathrm{~h}$ on stream. The measured temperatures and conversions for these experiments are given in Table 6 . The decrease in activity is faster then during the first long duration experiment. This may be caused by the fact that during the second continuous experiment on the average the temperature level in the reactor was higher, causing a more rapid deactivation. Comparing experiments $27 \mathrm{~S}, 33 \mathrm{~S}, 37 \mathrm{~S}$ and $45 \mathrm{~S}$ with experiments 19S, 21S, 23S and 25S it is clear that the deactivation is much faster during, or in between, short experiments than during continuous operation.

We conclude that the deactivation of the catalyst is fast and occurs mainly during the time the reactor stands idle in between experiments. During continuous operation the rate of deactivation is smaller. The fast deactivation is most probably a property of the specific model reaction we used.

\subsection{Regeneration}

For industrial application of a process it is important whether the catalyst can be regenerated in situ. To this end several regeneration experiments were performed. Prior to regeneration the catalyst bed was purged and dried thoroughly and preheated to $130^{\circ} \mathrm{C}$ using the heating jacket around the reactor. Then the regeneration was started at a slightly elevated pressure by feeding air to the bed. During regeneration the temperatures were recorded at the detection points. A typical plot of the temperatures versus time during the regeneration is given in Fig. 11 for a regeneration executed after the second long duration experiment. Due to a short interruption in the power supply no data were recorded in the period between 37 and $41 \mathrm{~h}$; the regeneration itself was not affected.

Table 5. Decrease in catalyst activity during continuous operation of the reactor at constant operating conditions

\begin{tabular}{ccccccc}
\hline $\begin{array}{c}\text { Time } \\
\text { (h) }\end{array}$ & $\begin{array}{c}\left.{ }^{T_{1}} \mathrm{C}\right) \\
\left({ }^{\circ} \mathrm{C}\right)\end{array}$ & $\begin{array}{c}T_{2} \\
\left({ }^{\circ} \mathrm{C}\right)\end{array}$ & $\zeta_{1}$ & $\zeta_{2}$ & $\zeta_{3}$ \\
\hline 10 & 78 & 89 & 93 & 0.27 & 0.65 & 0.67 \\
20 & 78 & 89 & 93 & 0.27 & 0.63 & 0.64 \\
30 & 77 & 86 & 90 & 0.27 & 0.61 & 0.61 \\
40 & 77 & 85 & 90 & 0.27 & 0.58 & 0.58 \\
50 & 76 & 85 & 88 & 0.27 & 0.55 & 0.55 \\
\hline
\end{tabular}

An interesting phenomenon is the presence of two temperature peaks in the first part of the catalyst bed. These multiple peaks cannot be easily explained; probably the burn-off reaction is ignited at several places in the reactor so that more than one reaction wave travels through the bed. It is observed that the height of the temperature peak decreases with increasing axial position in the bed; this is probably caused by a non-uniform profile of the deposits.

From Fig. 11 the velocity of the reaction front can be calculated as $3.3 \times 10^{-6} \mathrm{~m} / \mathrm{s}$ for the section between the first and second detection points, and as 4.4 $\times 10^{-6} \mathrm{~m} / \mathrm{s}$ for the section between the second and third detection points. Assuming that the burn-off reaction is $\mathrm{C}+\mathrm{O}_{2} \rightarrow \mathrm{CO}_{2}$, that the conversion rate of the deposits is limited by the interparticle mass transfer rate, that the reactor is adiabatic and that no axial dispersion of mass and heat occurs Westerterp et al. $(1984,1988)$ gave the following equation for the velocity $U_{\text {front }}$ of the reaction front:

$$
U_{\text {front }}=\frac{U_{\mathrm{G}} C_{\mathrm{A} 0}}{\varepsilon C_{\mathrm{A} 0}+\rho_{\mathrm{S}}(1-\varepsilon) C_{\mathrm{B} 0}^{\prime} \frac{v_{\mathrm{A}}}{v_{\mathrm{B}}}} .
$$

In this equation $U_{G}$ is the air flow in $\mathrm{m} / \mathrm{s}, C_{\mathrm{AO}}$ the oxygen concentration in the gas in $\mathrm{kmol} / \mathrm{m}^{3}, \rho_{\mathrm{S}}$ the bulk density of the solid phase in $\mathrm{kg} / \mathrm{m}^{3}, \varepsilon$ the bed porosity and $C_{B O}^{\prime}$ the concentration of the carbon deposit on the catalyst in $\mathrm{kmol} \mathrm{C} / \mathrm{kg}$ catalyst.

Using eq. (2) we can estimate the concentration of the carbon deposits. The regeneration was executed at a pressure of $0.3 \mathrm{MPa}$. With $\varepsilon=0.4, \rho_{\mathrm{s}}=1400 \mathrm{~kg} / \mathrm{m}^{3}$,

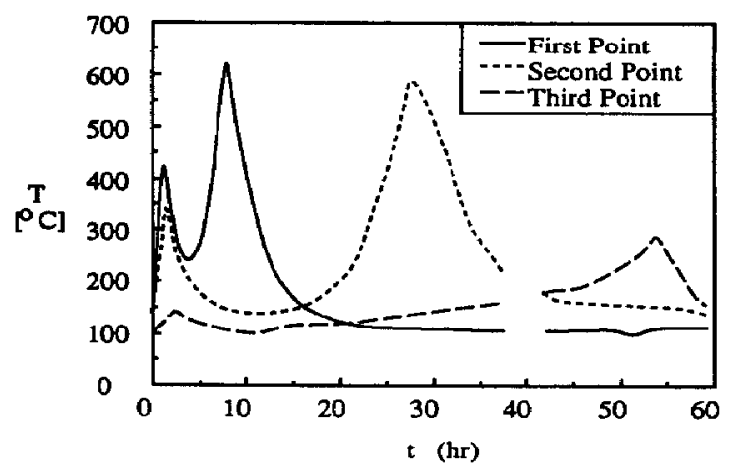

Fig. 11. Temperatures measured at the detection points during catalyst regeneration. Experimental conditions: $\Phi_{G}=2 \mathrm{Nl} / \mathrm{min}, P=0.3 \mathrm{MPa}, T_{0}=130^{\circ} \mathrm{C}$ and $L=0.95 \mathrm{~m}$.

Table 6. Decrease in catalyst activity during continuous operation with varying operating conditions

\begin{tabular}{rrrrrrrr}
\hline Code & $\begin{array}{c}T_{1} \\
\left({ }^{\circ} \mathrm{C}\right)\end{array}$ & $\begin{array}{c}T_{2} \\
\left({ }^{\circ} \mathrm{C}\right)\end{array}$ & $\begin{array}{c}T_{3} \\
\left({ }^{\circ} \mathrm{C}\right)\end{array}$ & $\zeta_{1}$ & $\zeta_{2}$ & $\zeta_{3}$ & $\zeta_{\mathrm{L}}$ \\
\hline $27 \mathrm{~S}$ & 88 & 101 & 103 & 0.42 & 0.79 & 0.85 & 0.99 \\
$33 \mathrm{~S}$ & 80 & 99 & 100 & 0.18 & 0.47 & 0.68 & 0.68 \\
$37 \mathrm{~S}$ & 79 & 93 & 99 & 0.19 & 0.46 & 0.65 & 0.67 \\
$45 \mathrm{~S}$ & 77 & 85 & 92 & 0.11 & 0.32 & 0.47 & 0.47 \\
\hline
\end{tabular}


$v_{\mathrm{A}}=v_{\mathrm{B}}=1, U_{\mathrm{G}}=1.44 \times 10^{-3} \mathrm{~m} / \mathrm{s}$ and $C_{\mathrm{AO}}=18.28$ $\times 10^{-3} \mathrm{kmol} / \mathrm{m}^{3}$ the carbon concentration $C_{\mathrm{BO}}^{\prime}$ can be calculated for both sections of the bed. In the first section $C_{\mathrm{BO}}^{\prime}=9.4 \times 10^{-3} \mathrm{kmol} C / \mathrm{kg}$ catalyst or $113 \mathrm{~g} \mathrm{C} / \mathrm{kg}$ catalyst, in the second section of the bed $C_{\mathrm{B} O}^{\prime}=7.1 \times 10^{-3} \mathrm{kmol} \mathrm{C} / \mathrm{kg}$ catalyst or $85.4 \mathrm{~g} \mathrm{C} / \mathrm{kg}$ catalyst. These values are reasonable realizing that it is definitely not true that the only reaction is the formation of carbon dioxide. During regeneration we noticed the formation of ammonia and of ammonium bicarbonate pointing to the presence of nitrogen- and hydrogen-containing deposits and to reactions other than just the formation of carbon dioxide. The lower value for the coke concentration in the second part of the reactor seems to contradict our earlier suggestion that the deactivation is faster in the second part of the reactor, but we should realize that the rate of deactivation not only depends on the actual amount of coke deposited on the catalyst surface, but also on its structure and composition. In our reactor with pronounced concentration profiles the structure and the composition of the deposits may well vary.

From a comparison between experiments $11 \mathrm{~S}$ and $18 \mathrm{~S}$ done before and after a regeneration it can be concluded that the initial activity of the catalyst is completely restored after the regeneration: the conversion and the temperature at the first two positions in the bed were practically equal. Regeneration of the last part of the catalyst bed apparently was not complete. Our results show that the catalyst can be regenerated with air under slightly elevated pressure if the bed is preheated to around $130^{\circ} \mathrm{C}$.

The air flow rate during the regeneration was extremely low. As a consequence heat dissipation was large and the maximum temperatures reached remained low. Under industrial circumstances regeneration must be executed much faster and then maximum temperatures will become much higher, unless the air is diluted with an inert gas like steam or nitrogen. However, it was our aim to investigate the feasibility of the regeneration of the catalyst in situ under mild operating conditions. Now this feasibility has been proven, further experiments are required to determine optimum regeneration conditions.

\section{DISCUSSION AND CONCLUSIONS}

We have presented experimental data on the threephase hydrogenation of trinitrotoluene to triaminotoluene in a cocurrent upflow packed bubble column reactor. Methanol was used as a solvent to absorb most of the reaction heat by evaporation. The influence of the main operating parameters, the hydrogen supply ratio $\alpha_{\mathrm{TAT}}$, the reactor pressure and the feed temperature were demonstrated experimentally.

We demonstrated that for $\alpha_{\text {TAT }}<1$ practically all hydrogen is consumed and the maximum conversion approaches the supply ratio. The hydrogen itself will not be consumed completely because in that case the hydrogen partial pressure would drop to zero, stopping the reaction. We showed that for $x_{\text {TAT }}<1$ the temperature level in the reactor increases with increasing $\alpha_{\text {TAT }}$ until it is close to the boiling point of the solvent at the prevailing pressure. For $\alpha_{\text {TAT }}>1$ the situation is more complex.

The reactor pressure determines the boiling point of the solvent. With increasing pressure the temperature level in the reactor rises which results in an increase of the conversion as long as it is not yet complete.

The influence of the feed temperature is moderated by the evaporation. A change in the feed temperature will result in a smaller change in the temperature at the entrance of the catalyst bed. We found that the catalyst deactivates quickly. The rate of deactivation was faster for experiments with a period in between, during which the reactor stands idle. We suggested that the deactivation may continue during the idle periods and is caused by the presence of reaction intermediates in the highly porous catalyst carrier.

For industrial application it is very important to know whether the catalyst can be regenerated. We showed that the catalyst can be regenerated in situ with air under slightly elevated pressure. From standard experiments we concluded that the original activity had been recuperated after the regeneration.

On the basis of results obtained up to now we feel confident that eventually the packed bubble column reactor can be developed as a good catalytic hydrogenation reactor for multiproduct use in fine chemical plants, requiring an occasional catalyst regeneration.

Acknowledgements - This investigation was supported by the Netherlands Foundation for Chemical Research with financial aid from the Netherlands Technology Foundation. The authors wish to thank A. H. Pleiter, K. van Bree, H. J. Vunderink and W. Leppink for their excellent technical support and H. J. L. J. van der Linden for his coordinating efforts.

\section{NOTATION}

$C_{i} \quad$ concentration of component $i, \mathrm{kmol} / \mathrm{m}^{3}$

$C_{B 0}^{\prime} \quad$ coke concentration on the catalyst, $\mathrm{kmol}$ $\mathrm{C} / \mathrm{kg}$ catalyst

DANT diaminonitrotoluene

DNHAT dinitrohydroxylaminetoluene

$E_{\alpha i}$

$H_{\alpha i}$

$k_{i}$ activation temperature in reaction velocity constant, $K$

activation temperature in adsorption constant, $\mathbf{K}$

reaction velocity constant for the reaction of component $i$ to component $i+1$, $\mathrm{kmol} / \mathrm{m}^{3} \mathrm{~s}$

$k_{i \infty} \quad$ pre-exponential constant in reaction velocity constant, $\mathrm{kmol} / \mathrm{kg}$ catalyst s

$K_{i} \quad$ adsorption constant for component $i$, $\mathrm{m}^{6} / \mathrm{kmol}$

$K_{i \infty} \quad$ pre-exponential constant in adsorption constant, $\mathrm{m}^{3} / \mathbf{k m o l}$

$L \quad$ reactor length, $\mathrm{m}$

$m_{\text {cat }} \quad$ mass of catalyst, $\mathrm{kg}$ catalyst $/ \mathrm{m}^{3}$ reactor

Nl litre at normalized conditions $(P=0.1$

$\mathrm{MPa}$ and $T=0^{\circ} \mathrm{C}$ )

$P \quad$ total pressure, $\mathrm{N} / \mathrm{m}^{2}$ 
$P_{i} \quad$ partial pressure of component $i, \mathrm{~N} / \mathrm{m}^{2}$

$r_{i} \quad$ reaction rate for reaction of $i \rightarrow i+1$, $\mathrm{kmol} / \mathrm{m}^{3} \mathrm{~s}$

$R \quad$ gas constant, $\mathrm{J} / \mathrm{mol} \mathrm{K}$

$T \quad$ temperature, ${ }^{\circ} \mathrm{C}$

TAT 2,4,6-triaminotoluene

TNT 2,4,6-trinitrotoluene

$U_{\text {front }} \quad$ velocity of reaction front during regeneration, $\mathrm{m} / \mathrm{s}$

$U_{G} \quad$ superficial gas velocity at reactor conditions based on the empty cross-section of the column, $\mathrm{m} / \mathrm{s}$

$\alpha_{\text {TAT }}$ hydrogen supply ratio defined as the ratio of the number of moles of hydrogen fed to the reactor to the number of moles of hydrogen needed for complete conversion of TNT to TAT

dimensionless ratio of the number of moles of liquid fed to the reactor to the number of moles of gas fed to the reactor: $\gamma=\phi_{\mathrm{L}} / \phi_{\mathrm{G}}$

$\phi$

$\Phi_{\mathbf{L}}$

$\Phi_{\mathrm{G}}$

Indices

1

2

3

L

at the first detection point at the second detection point at the third detection point at the reactor exit

\section{REFERENCES}

Janssen, H. J., Vos, H. J. and Westerterp, K. R., 1987, Katalystisch hydrogeneren in een doorstroomde geroerde tankreactor, I2 ${ }^{2}$ Procestechnologie 1, 23-28.

van Gelder, K. B., 1988, A packed bubble column reactor; use of an evaporating solvent. Ph.D. thesis, Twente University of Technology.

van Gelder, K. B. and Westerterp, K. R., 1990, Residence time distribution and holdup in a cocurrent upflow packed bed reactor at elevated pressure and low Reynolds numbers. Chem. Engng Technol, 13, 27-40.

van Gelder, K. B., Borman, P. C., Weenink, R. E. and Westerterp, K. R., 1990, Three-phase packed bed reactor with an evaporating solvent -II. Modelling of the reactor. Chem. Engng Sci. 45, 3171-3192.

Westerterp, K. R. and Crombeen, P. R. J. J., 1983, Thermal behaviour of agitated gas-liquid reactors with a vaporizing solvent/air oxidation of hydrocarbons. Chem. Engng Sci. 38, 1331-1340.

Westerterp, K. R., van Swaaij, W. P. M. and Beenackers, A. A. C. M., 1984, Chemical Reactor Design and Operation, 2nd Edn. John Wiley, Chichester.
Westerterp, K. R., Fontein, H. J. and van Beckum, F. P. H., 1988, Decoking of fixed bed catalytic reactors. Chem. Engng. Technol 11, 367-375.

\section{APPENDIX: INFLUENCE OF PRESSURE AND GAS FLOW RATE ON THE EVAPORATION FLUX}

The influence of the reactor pressure and of the hydrogen supply ratio on the evaporation rate can be illustrated as follows. Suppose in a gas-liquid bubble column at the bottom we feed $\phi_{0} \mathrm{~mol} / \mathrm{s}$ of an inert, insoluble gas. We assume that the pressure in the system $P_{s}$, the temperature and the gas hold-up are constant and that the gas and the liquid phase behave ideally. Part of the liquid phase will evaporate. This evaporation will continue until the partial pressure of the liquid in the gas phase is equal to the vapour pressure of the liquid at the system temperature $P_{L}^{0}$. Thus a solvent vapour stream of $\phi_{\mathrm{ev}} \mathrm{mol} / \mathrm{s}$ flows from the liquid to the gas phase as given schematically in Fig. 12.

For the gas flow leaving the system we can write:

$$
\phi_{\text {out }}=\phi_{\mathrm{o}}+\phi_{\mathrm{ev}}
$$

and for the pressure at the exit:

$$
P_{\mathrm{s}}=P_{\text {inert }}+P_{\mathrm{L}}^{0}
$$

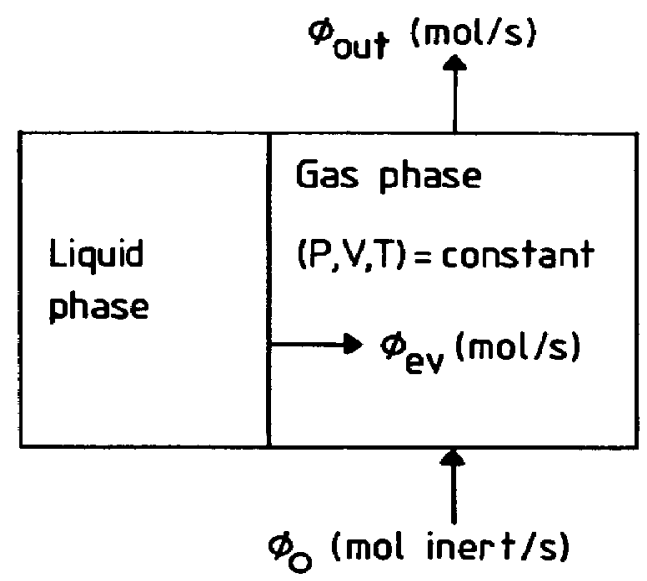

Fig. 12. Evaporation in an isothermic gas-liquid system.

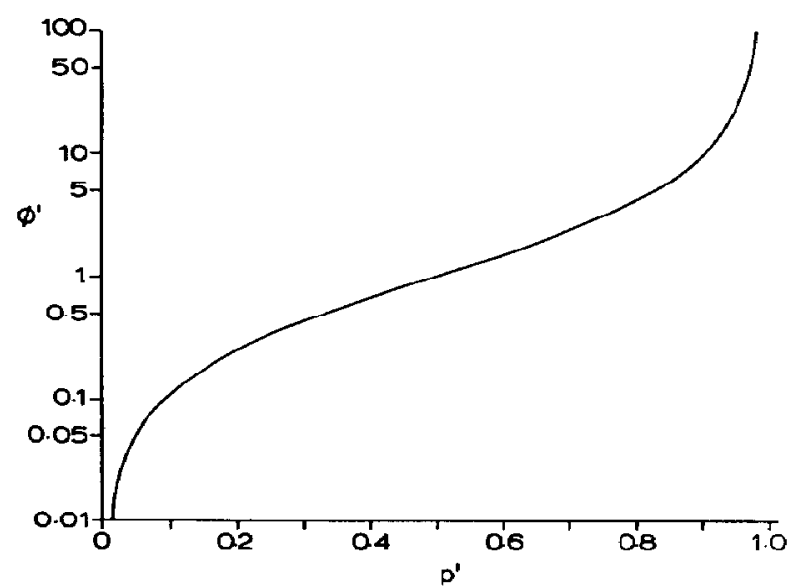

Fig. 13. Relative evaporation rate as a function of the relative vapour pressure in an isothermic gas-liquid system. 
Assuming ideal behaviour of the gas phase we can write for and

Q.v:

$$
\phi_{\mathrm{ev}}=\frac{P_{\mathrm{L}}^{0}}{P_{\mathrm{e}}} \phi_{\mathrm{out}}
$$

and thus:

$$
\frac{\phi_{\text {ev }}}{\phi_{\text {out }}}=\frac{\phi_{\text {ev }}}{\phi_{\mathrm{o}}+\phi_{\mathrm{ev}}}=\frac{P_{\mathrm{i}}^{0}}{P_{\mathrm{a}}}=P^{\prime},
$$

in which $P^{\prime}$ is the relative vapour pressure of the liquid. For the relative evaporation rate $\phi^{\prime}=\phi_{\text {ev }} / \phi_{0}$ we find:

$$
\phi^{\prime}=\frac{P^{\prime}}{1-P^{\prime}}
$$

$$
\frac{\mathrm{d} \phi^{\prime}}{\mathrm{d} \boldsymbol{P}^{\prime}}=\frac{1}{\left(1-P^{\prime}\right)^{2}}
$$

Equation (AS) is given graphically in Fig. 13. We see that the evaporation rate $\left(\phi^{\prime} \cdot \phi_{0}\right)$ will increase with increasing inert gas feed rate (at constant temperature and system pressure). The influence of the system pressure is rather surprising: increasing the reactor pressure $P_{\mathrm{g}}$ decreases $P^{\prime}-P_{L}^{0}$ is constant because the temperature is constant-and thus at constant $\phi_{0}$ the evaporation rate will decrease with increasing $P_{s}$. Further, we see that the evaporation rate increases to infinity close to the boiling point of the liquid where $P^{\prime} \rightarrow 1$. 